University of Nebraska - Lincoln

DigitalCommons@University of Nebraska - Lincoln

Faculty Publications from the Department of Electrical \& Computer Engineering, Department Electrical and Computer Engineering

$11-26-2006$

\title{
KrF excimer laser-assisted combustion-flame deposition of diamond films
}

\author{
Y. X. Han \\ Hao Ling \\ University of Nebraska-Lincoln, hling4@unl.edu \\ Yongfeng Lu \\ University of Nebraska-Lincoln, ylu2@unl.edu
}

Follow this and additional works at: https://digitalcommons.unl.edu/electricalengineeringfacpub

Part of the Electrical and Computer Engineering Commons

Han, Y. X.; Ling, Hao; and Lu, Yongfeng, "KrF excimer laser-assisted combustion-flame deposition of diamond films" (2006). Faculty Publications from the Department of Electrical and Computer Engineering. 89.

https://digitalcommons.unl.edu/electricalengineeringfacpub/89

This Article is brought to you for free and open access by the Electrical \& Computer Engineering, Department of at DigitalCommons@University of Nebraska - Lincoln. It has been accepted for inclusion in Faculty Publications from the Department of Electrical and Computer Engineering by an authorized administrator of DigitalCommons@University of Nebraska - Lincoln. 


\title{
KrF excimer laser-assisted combustion-flame deposition of diamond films
}

\author{
Y. X. Han, H. Ling, and Y. F. Lu ${ }^{a)}$ \\ Department of Electrical Engineering, University of Nebraska-Lincoln, Lincoln, Nebraska 68588-0511
}

(Received 2 July 2006; accepted 18 October 2006; published online 26 December 2006)

\begin{abstract}
Cobalt (Co) composition has detrimental effects on the deposition of diamond films on cemented tungsten carbide (WC-Co) substrates. It decreases adhesion of the deposited films to the substrates and causes a transformation of $s p^{3}$-bonded diamond to $s p^{2}$-bonded graphite. In this study, a $\mathrm{KrF}$ excimer laser with a wavelength of $248 \mathrm{~nm}$, a pulse width of $23 \mathrm{~ns}$, and a pulse energy range of 84-450 mJ was used in the combustion-flame method to improve the quality of the deposited diamond films. Scanning electron microscopy, energy dispersive x-ray analysis, and Raman spectroscopy of the deposited films showed that a laser irradiation during combustion-flame deposition of diamond decreased the cobalt composition drastically. Based on the experimental results, the influence of the laser irradiation on the deposition process was analyzed. (C) 2006 American Institute of Physics. [DOI: 10.1063/1.2402977]
\end{abstract}

\section{INTRODUCTION}

Diamond coatings are of great interest to industrial applications and scientific research due to their unique properties such as high hardness, high thermal conductivity, chemical inertness, wear resistance, transparency, and high electrical resistivity. ${ }^{1}$ Many techniques, including chemical vapor deposition (CVD), ${ }^{2,3}$ pulsed laser deposition (PLD), ${ }^{4}$ and shock wave compression technique ${ }^{5,6}$ have been developed to deposit diamond films on various substrates. However, most of the deposition techniques require high temperature and high pressure, or are based on the reaction of special gases (e.g., $\mathrm{CH}_{4}, \mathrm{H}_{2}$, etc.) in a vacuum chamber, which limit their potential for a large-scale production. Up to now, the only published technique that can obtain diamond films in open atmosphere is the combustion-flame method, ${ }^{7-10}$ which uses the flame of $\mathrm{C}_{2} \mathrm{H}_{2}$ (or other hydrocarbon gases) and $\mathrm{O}_{2}$ gases to create a reaction zone for diamond growth. QQC Inc., a Michigan-based company, applied patents ${ }^{11,12}$ for their unique technique using three lasers with $\mathrm{CO}_{2}$ and $\mathrm{N}_{2}$ gases in open atmosphere to obtain high-quality diamond films. But the data in their patents are very limited and few groups could repeat their experimental results in the past years.

Since the invention of the combustion-flame method by Hirose and Komaki in $1988,{ }^{13}$ many researchers have made tremendous efforts to improve the technique to obtain highquality and uniform diamond films. The most significant parameters in this technique are the gas ratio, the total flow rate, the growth temperature, and the distance between the substrate surface and the inner cone of the flame. ${ }^{7}$ It is generally agreed that diamond growth can be achieved by a gas ratio $\left(\mathrm{C}_{2} \mathrm{H}_{2} / \mathrm{O}_{2}\right)$ of $0.9-1.2^{14}$ and a temperature range of $400-1200{ }^{\circ} \mathrm{C}$. $^{7}$ Abe et al. ${ }^{15}$ obtained highly uniform and dense diamond microcrystalline thin films using a combustion flame surrounded by an inert gas flow. Thorpe et al. ${ }^{16}$ used a growth-etch cycling method to achieve high-quality diamond. By placing the flame in an enclosed chamber,

\footnotetext{
a) Author to whom correspondence should be addressed; electronic mail: ylu2@unl.edu
}

Takeuchi and Murakawa ${ }^{17}$ reduced the effect of $\mathrm{N}_{2}$ composition in open air. Donnet et al. ${ }^{18}$ treated WC-Co substrates in a boiling solution of $17 \% \mathrm{HCl}$ to minimize the Co content and increase the roughness on substrate surfaces for better deposition. All these research efforts improved the technique in certain aspects.

In this study, a $\mathrm{KrF}$ excimer laser was used with a combustion flame to deposit diamond coatings on WC-Co substrates. The objectives of this work were to obtain an understanding of the interactions and effects of pulsed laser irradiation on the diamond growth, and to explore the conditions that could achieve better diamond film quality.

\section{EXPERIMENTAL SETUP}

Figure 1 shows a schematic diagram of the experimental setup used in this study, which contains a KrF excimer laser (COMPexPro 205, Lambda Physik), optics for directing the laser beam, a commercial $\mathrm{C}_{2} \mathrm{H}_{2} / \mathrm{O}_{2}$ combustion-flame welding torch, a gas supply, and a water-cooling system. The welding torch had an orifice with a diameter of $1.5 \mathrm{~mm}$. The gas ratio of $\mathrm{C}_{2} \mathrm{H}_{2} / \mathrm{O}_{2}$ was controlled to be 0.90 by flow meters (B7920V, Spec-Air Gases \& Technologies) and the total gas flow was settled at $2.38 \mathrm{slm}$ (standard liters per minute). WC-Co substrates were placed on the surface of a hollow brass block with water coming in from one side and going out from the other side. The distance between the sub-

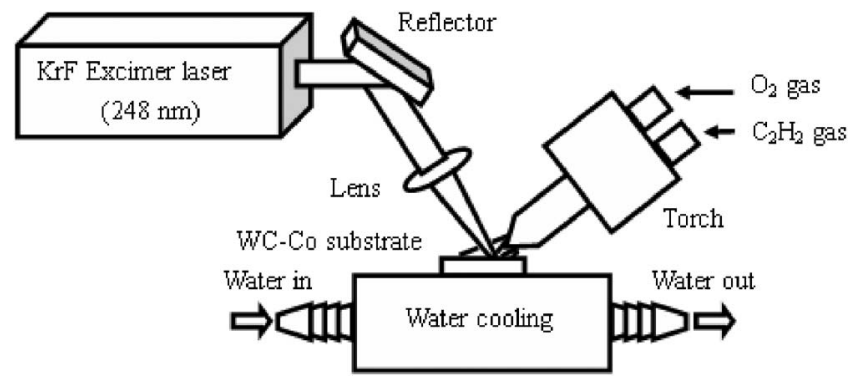

FIG. 1. Schematic experimental setup for laser-assisted combustion-flame deposition of diamond films on WC-Co substrates. 


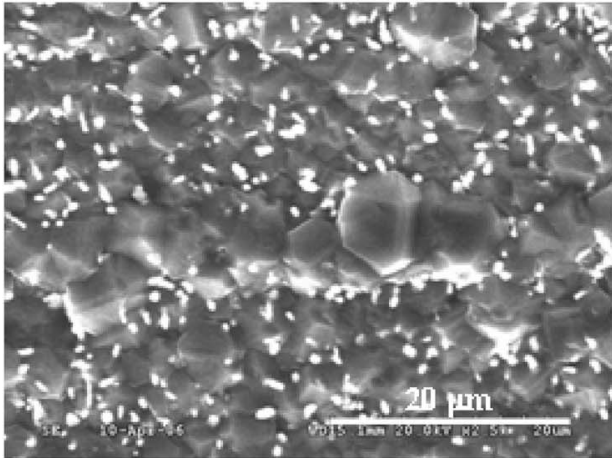

(a)



(c)

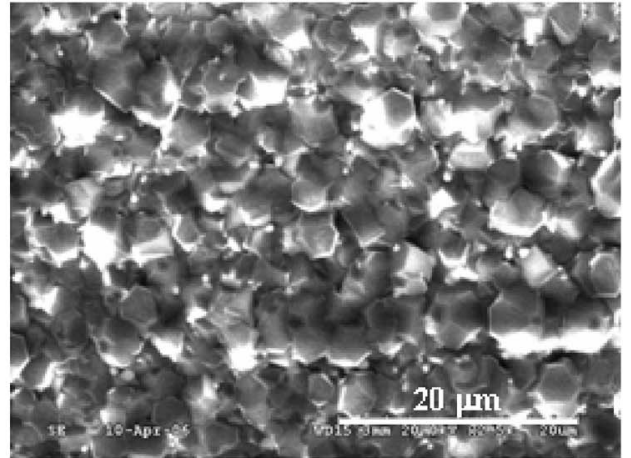

(b)

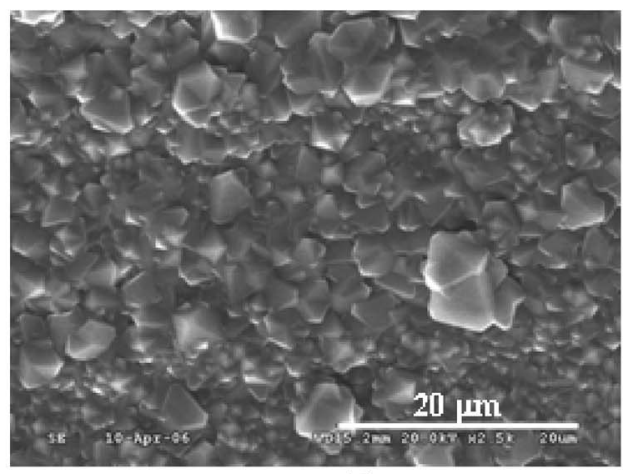

(d)
FIG. 2. SEM images of the center of diamond films after $15 \mathrm{~min}$ deposition: (a) no laser irradiation, and with a pulsed $\mathrm{KrF}$ excimer laser irradiation at $1 \mathrm{~Hz}$ with fluences of (b) 142, (c) 247 , and (d) $361 \mathrm{~mJ} / \mathrm{cm}^{2}$. strate surfaces to the inner cone of the flame was $1 \mathrm{~mm}$. A $\mathrm{KrF}$ excimer laser beam with a wavelength of $248 \mathrm{~nm}$, a pulse width of $23 \mathrm{~ns}$, and a pulse energy range of 84-450 mJ was directed by mirrors and focused by a convex lens with a focusing length of $150 \mathrm{~mm}$ to the substrate surfaces right under the flame. The incident angle of the laser beam was fixed at $35^{\circ}$ to the normal of the substrate surfaces. The flowing direction of the flame was kept at $55^{\circ}$ to the normal of the substrate surfaces. The laser beam covered the whole deposition area. Deposition time was $15 \mathrm{~min}$. The WC-Co substrates (BS-6S, Basic Carbide Corp.) with a dimension of $25.4 \times 25.4 \times 1.6 \mathrm{~mm}^{3}$, a Co composition of $6 \%$, and a surface roughness of $0.40 \mu \mathrm{m}$ were ultrasonically cleaned in an acetone liquid for $30 \mathrm{~min}$ before deposition. The surface temperature of the substrates was monitored during deposition by a pyrometer (OS3752, Omega Engineering, Inc.) and was controlled to be $750{ }^{\circ} \mathrm{C}$ by varying the contact condition between the substrates and the watercooling brass block. The repetition rate of the laser pulse was set to be $1 \mathrm{~Hz}$ and the incident laser fluence on the substrate surfaces was varied. After each experiment, an Ar gas flow was used to replace the flame immediately to protect the substrate surfaces from being oxidized.

A scanning electron microscope (SEM) (Hitachi S-3000N) was used to characterize the morphologies of the deposited films. The SEM has an Oxford Inca energy dispersive $\mathrm{x}$-ray (EDX) analysis system with a light element $\mathrm{x}$-ray detector [15 mm working distance; distance between focal plane and detector (WD)] and has a spectrum imaging software which allows spectra to be collected corresponding to the SEM images. The thickness of the deposited films was characterized by a stylus profilometer (XP-2, Ambios Technology). A homemade Raman system, ${ }^{19}$ consisting of a
514.5 nm Ar ion laser (Innova 300, Coherent, Inc.), a triplegrating dispersive imaging spectrograph (SP-2300i, Princeton Instrument) equipped with a charge-coupled device (CCD) camera (PIXIS 400B, Princeton Instrument), and optics, was used to examine the bonding structures in the films. The Ar ion laser power used was between 20 and $30 \mathrm{~mW}$, which produced efficient Raman excitation while maintaining no damage to the examined area. The laser beam was focused to a spot diameter of approximately $2 \mu \mathrm{m}$. Prior to and after Raman characterization of the deposited films, the Raman system was calibrated and rechecked using a Si substrate and a pure graphite plate. Three spectra at different positions of each film were recorded and averaged to minimize the random effects.

\section{RESULTS AND DISCUSSION}

\section{A. Film morphology}

Diamond films were obtained after 15 min deposition under all conditions with and without laser irradiation. The morphologies of deposited films were studied with a SEM. The images at the center of the films are shown in Fig. 2. In all cases, deposited films consist of polycrystalline grains. It is observed that in the case without laser irradiation, as shown in Fig. 2(a), the film was interspersed by impurities (tiny white spots) with a diameter of around $1 \mu \mathrm{m}$. When a $\mathrm{KrF}$ excimer laser beam with a repetition rate of $1 \mathrm{~Hz}$ and a fluence of $142 \mathrm{~mJ} / \mathrm{cm}^{2}$ was introduced during the deposition process, there were fewer impurities in the obtained film, as shown in Fig. 2(b). If the laser fluence was increased to $247 \mathrm{~mJ} / \mathrm{cm}^{2}$, almost no impurities could be observed, as in 


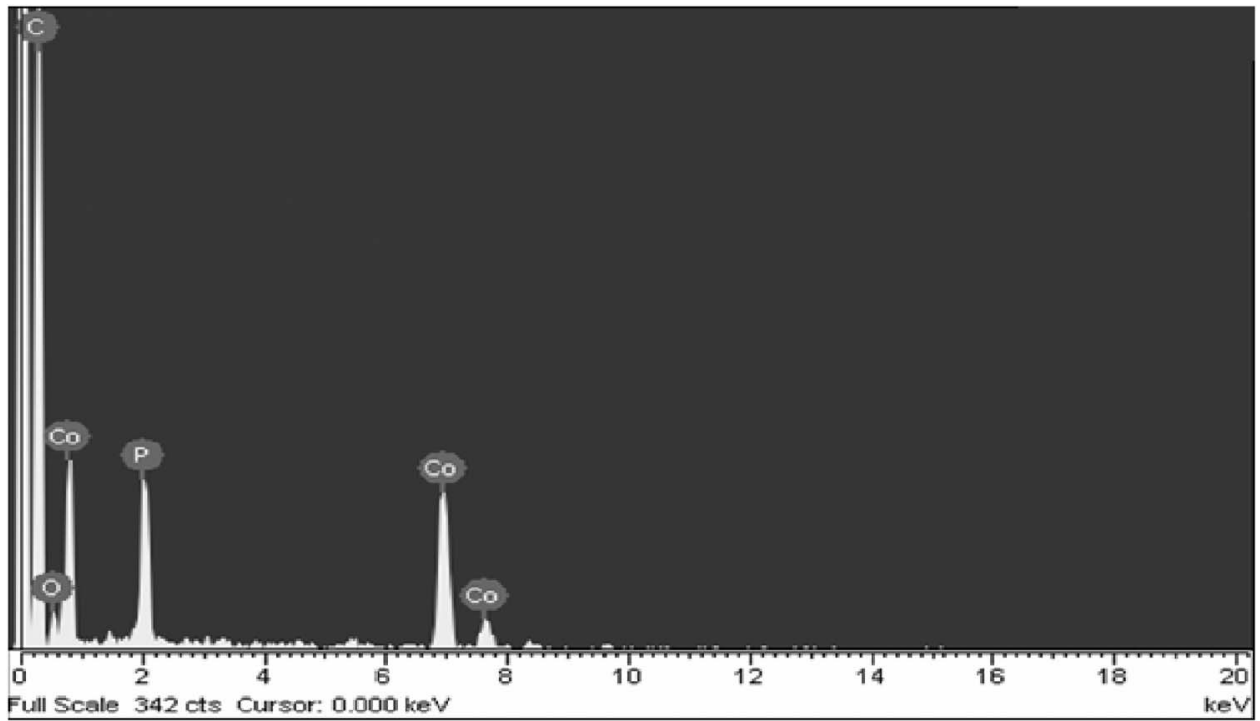

FIG. 3. An EDX spectrum of the impurities (white spots) dispersed on the deposited diamond films.

the case of Fig. 2(c). With a higher laser fluence, $361 \mathrm{~mJ} / \mathrm{cm}^{2}$, a similar result was obtained, and the SEM image is shown in Fig. 2(d).

From the SEM images shown in Fig. 2, it is also noticed that the average diamond crystal size became smaller when a laser irradiation was introduced. Under current experimental parameters, the higher the laser fluence was, the smaller the diamond crystals were. The film thickness was examined by a stylus profiler to be about $5 \mu \mathrm{m}$ in the center of the films in all cases, which meant similar diamond growth rates. The change in crystal size could be explained by the fact that higher laser energy introduced more crystal defects during deposition, and each defect could serve as a new site for a secondary nucleation. Since the flow rate and the gas ratio were fixed, the $\mathrm{C}$ source was unchanged. Under a fixed deposition time, the incoming $\mathrm{C}$ atoms were distributed to the newly introduced nuclei, and thus led to smaller crystal sizes.

\section{B. Film composition}

An EDX analysis associated with SEM was used to characterize the composition of deposited films. Figure 3 shows an EDX spectrum of the impurities presented in Figs. 2(a) and 2(b). It can be seen that there was high content of Co and $\mathrm{O}$ in the impurities. Donnet et al. ${ }^{18}$ explained the diffusion of Co in diamond films synthesized by a combustion flame as a thermally induced process. At high substrate temperatures, ball-shaped Co particles were formed on the substrate surfaces at initial deposition times. The $\mathrm{Co}$ atoms interacted with $\mathrm{C}$ atoms and were transformed to $\mathrm{C}$-saturated Co. The growth of diamond crystals developed a displacement of $\mathrm{Co}$, and the particles were reassembled and increased in size. The defects around Co particles provided sites for a secondary diamond nucleation, which, in turn, could displace the Co particles. With the increase in deposition time, diamond crystals could grow over some Co particles, but a large number of Co containing particles attached on the diamond facets were moved to the top surface and eventually fell together.

Table I shows a quantitative EDX analysis of the composition in the deposited films according to the SEM images in Figs. 2(a)-2(d). From Table I, it could be observed that the main composition in all films was $\mathrm{C}$, which was in agreement with the diamond crystals observed in Fig. 2. It is also noticed that there were $\mathrm{O}$ and Co compositions in all films. The $\mathrm{O}$ composition was introduced either by flame reaction during the deposition or by the intermittent retraction of the flame and replacement of the Ar gas. The Co composition was from the WC-Co substrates. From Table I, it was observed that with the increase in laser fluence, the $\mathrm{C}$ composition increased and the Co composition decreased correspondingly.

The absence of Co particles in Figs. 2(c) and 2(d) could possibly be explained by the laser cleaning effect. ${ }^{20,21}$ During the deposition process, diamond crystals were formed on substrate surfaces while Co composition came out of the substrates and formed Co particles due to high temperature. ${ }^{18}$ The adhesion force between the Co particles and the substrate surfaces was mainly van der Waals force. Under a laser pulse, the Co particles absorbed the laser energy, causing an abrupt thermal expansion which occurred within a very short period of time, resulting in a large acceleration sufficient to eject the Co particles from the substrate surfaces. Since diamond has a poor absorption of the laser light, the cleaning efficiency for the synthesized diamond crystals was much lower. Most of the diamond crystals remained on the substrate surfaces and served as nuclei for further growth.

\section{Film structures}

The atomic bonding structures in the deposited films were characterized by a homemade Raman system. ${ }^{19}$ Figure 4 shows a series of Raman spectra corresponding to the de-

TABLE I. Composition of diamond films (at. \%) after 15 min deposition: (a) no laser irradiation, and with $\mathrm{KrF}$ excimer laser irradiation at $1 \mathrm{~Hz}$ with fluences of (b) 142, (c) 247, and (d) $361 \mathrm{~mJ} / \mathrm{cm}^{2}$.

\begin{tabular}{crrrr}
\hline \hline Element & Film a & Film b & Film c & Film d \\
\hline C & 94.31 & 97.57 & 97.82 & 97.89 \\
O & 4.12 & 1.51 & 2.09 & 1.95 \\
Co & 1.20 & 0.68 & 0.09 & 0.08 \\
\hline \hline
\end{tabular}



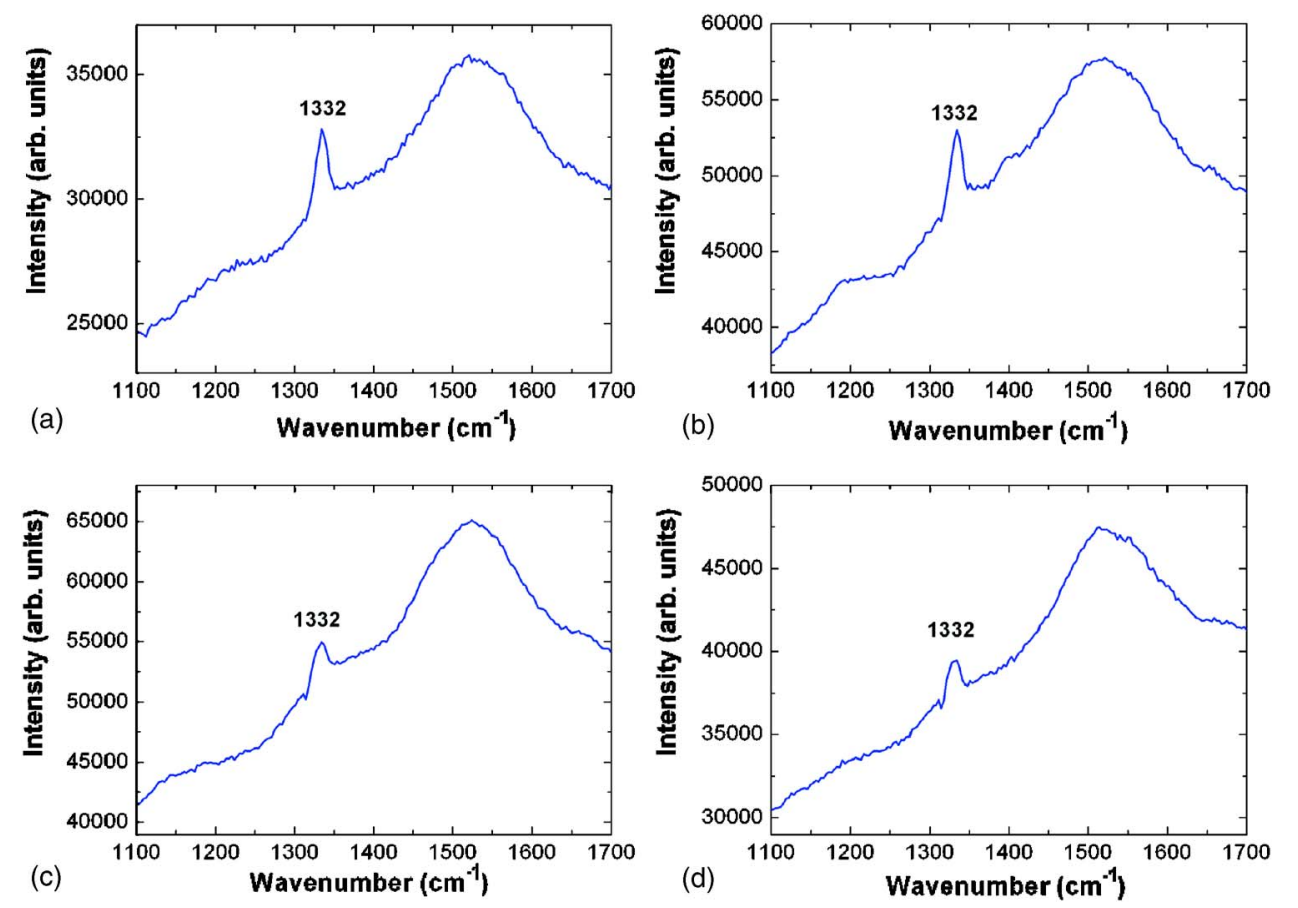

FIG. 4. (Color online) Raman spectra of the center of diamond films after 15 min deposition: (a) no laser irradiation, and with a pulsed $\mathrm{KrF}$ excimer laser irradiation at $1 \mathrm{~Hz}$ with fluences of (b) 142, (c) 247, and (d) $361 \mathrm{~mJ} / \mathrm{cm}^{2}$. posited films shown in Figs. 2(a)-2(d), respectively. The sharp peaks due to diamond were detected at $1332 \mathrm{~cm}^{-1}$, which correspond to low stressed diamond films. The broad peaks centered at $\sim 1520 \mathrm{~cm}^{-1}$ stand for amorphous (nanocrystalline) carbon. This means that the films consisted of diamond crystals in a matrix of amorphous carbon. However, from literature ${ }^{22}$ the sensitivity of the Raman spectroscopy to the $s p^{2}$ carbon hybridization-bond phase is about 50 times greater than that of the $s p^{3}$ diamond hybridization-bond phase. Thus the films were predominantly composed of diamond crystals. Under current experimental conditions, no crystalline $\left(1580 \mathrm{~cm}^{-1}\right)$ or microcrystalline $\left(1350 \mathrm{~cm}^{-1}\right)$ graphite phonons ${ }^{23}$ were observed in the Raman spectra.

The quality of the deposited diamond films was characterized by the ratio of diamond to amorphous carbon $\left(1332 \mathrm{~cm}^{-1} / 1520 \mathrm{~cm}^{-1}\right)$ peak heights, ${ }^{23} R_{\mathrm{dc}}$, in the Raman spectra and was plotted versus laser fluence, as shown in Fig. 5. The highest-quality diamond, as determined by the ratio,

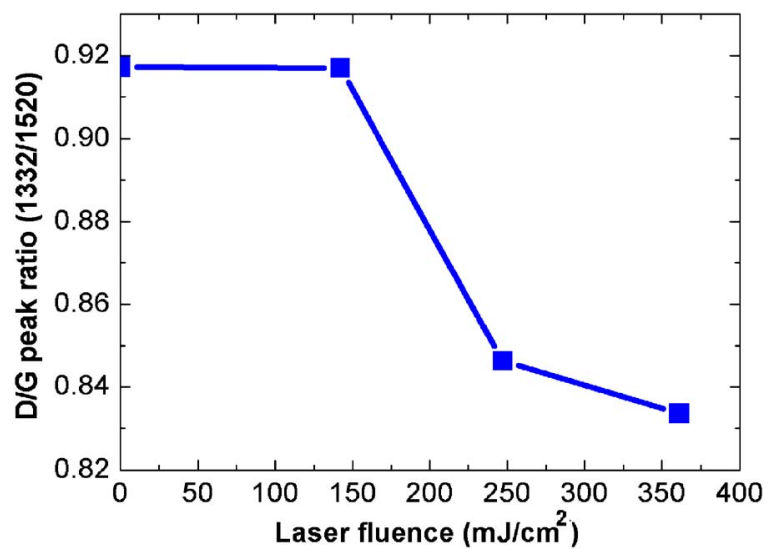

FIG. 5. (Color online) Ratio of the diamond Raman peak intensity $\left(1332 \mathrm{~cm}^{-1}\right)$ to the amorphous carbon peak intensity $\left(1520 \mathrm{~cm}^{-1}\right)$ as a function of the laser fluence. was obtained when there was no laser involved. When a laser beam was introduced in the process, the diamond quality decreased. Higher laser fluences produced diamond with lower quality. However, it is noticed from Fig. 5 that a lowfluence laser beam $\left(142 \mathrm{~mJ} / \mathrm{cm}^{2}\right)$ did produce similar diamond quality as the case without laser irradiation. Referring to the SEM images presented in Fig. 2 and EDX analysis in Table I, it could be concluded that the deposition process with a laser fluence of $142 \mathrm{~mJ} / \mathrm{cm}^{2}$ was optimal, with low Co impurities in the film and high diamond quality.

It is well known that diamond is a metastable form of carbon at low temperatures. At high temperatures or with external actions such as ultrashort laser pulses or high-energy electron/ion beam irradiation, it tends to transform to its stable form of graphite. ${ }^{24}$ The increased composition of $s p^{2}$-bonded composition (amorphous carbon and graphite) with higher laser fluences in this study was due to laserinduced graphitization of diamond. ${ }^{24-26}$ Higher laser fluences produced more photons, which were absorbed by the surface carbon atoms and assisted their transition from a diamond state ( $s p^{3}$ bonding) to a graphite or amorphous state $\left(s p^{2}\right.$ bonding). Laser energy might have other functions which potentially affect the diamond deposition process. More investigations are being carried out.

The Raman spectroscopy of a single diamond grain was performed with a commercial micro-Raman system (Renishaw inVia Raman Microscope). The Raman spectrum is shown in Fig. 6. The Raman system consists of a $488 \mathrm{~nm} \mathrm{Ar}$ ion laser and an integrated confocal microscope. Prior to the characterization, the system was calibrated using a Si substrate, and a Raman shift at $520 \mathrm{~cm}^{-1}$ was detected. From Fig. 6, both a sharp diamond peak at $1337 \mathrm{~cm}^{-1}$ and a lowintensity broad peak at $1550 \mathrm{~cm}^{-1}$ indicate that the diamond crystal is of high quality. 


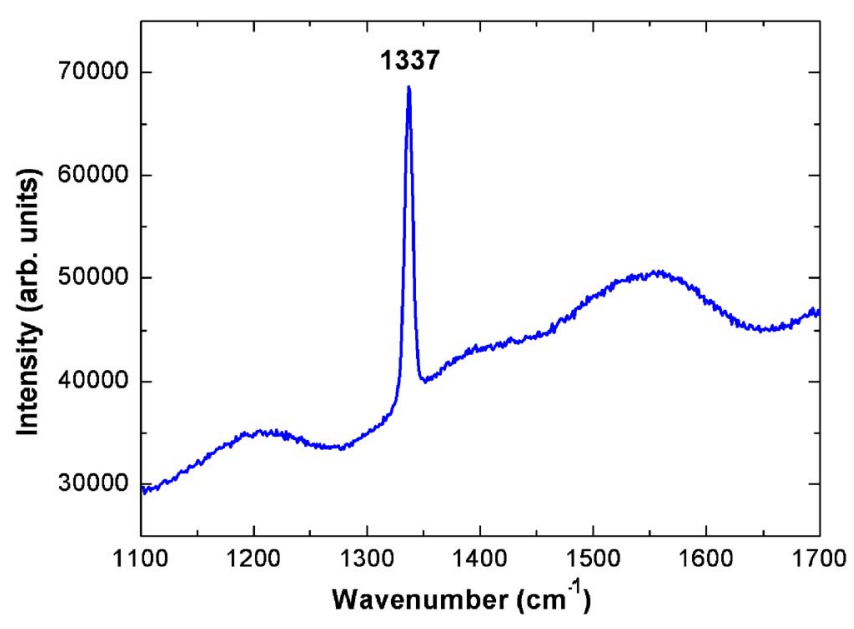

FIG. 6. (Color online) A Raman spectrum of a diamond grain at the film center after 15 min deposition without laser irradiation.

\section{CONCLUSIONS}

Diamond films were obtained on WC-Co substrates in open atmosphere using a $\mathrm{C}_{2} \mathrm{H}_{2} / \mathrm{O}_{2}$ combustion flame combined with a $\mathrm{KrF}$ excimer laser irradiation. SEM images showed that after 15 min deposition the films consisted of $\mathrm{C}$-saturated Co particles. The laser irradiation was found to reduce the Co impurities, while it decreased the crystal size of the synthesized diamond. The removal of Co impurities was possibly due to the laser cleaning effect, while the decrease in crystal size was explained by the fact that the laserinduced crystal defects provided more nuclei for a secondary diamond nucleation. Raman spectra of the deposited films showed that the introduction of a high-fluence laser irradiation decreased the diamond quality. It was found that under current experimental conditions, a laser fluence of $142 \mathrm{~mJ} / \mathrm{cm}^{2}$ was optimal to produce high-quality diamond films with low Co impurities.

\section{ACKNOWLEDGMENTS}

The authors would like to thank Dr. D. Doerr and Dr. D. Alexander of the Department of Electrical Engineering at the University of Nebraska-Lincoln (UNL) for providing convenient access to their SEM, Dr. N. Ianno for offering access of his stylus profilometer, Dr. Y. Zhou of the Beadle Center at UNL for help on SEM and EDX, and Dr. S. W. Martin and his students of the Department of Materials Science and Engineering at the Iowa State University for their help on the micro-Raman system. The homemade Raman system was built by K. J. Yi, who the authors would like to thank for great efforts. This work was financially supported by the U.S. Office of Naval Research (ONR) through the Multidisciplinary University Research Initiative (MURI) Program.

${ }^{1}$ Y. F. Lu, S. M. Huang, X. B. Wang, and Z. X. Shen, Appl. Phys. A: Mater. Sci. Process. 66, 543 (1998).

${ }^{2}$ J. Wei, J. M. Chang, and Y. Tzen, Thin Solid Films 212, 91 (1992).

${ }^{3}$ D. Michau, B. Tanguy, and G. Demazeau, Mater. Lett. 17, 192 (1993).

${ }^{4}$ M. Novotny, M. Jelinek, J. Bulir, J. Lancok, V. Vorlicek, and J. Bonarski, Appl. Phys. A: Mater. Sci. Process. 79, 1267 (2004).

${ }^{5}$ O. G. Epanchintsev, A. S. Zubchenko, A. E. Korneyev, and V. A. Simonov, J. Phys. Chem. Solids 58, 1785 (1997).

${ }^{6}$ D. J. Erskine and W. J. Nellis, Nature (London) 349, 317 (1991).

${ }^{7}$ T. L. Huu, H. Zaidi, and D. Paulmier, Thin Solid Films 308, 147 (1997).

${ }^{8}$ J. B. Donnet, H. Oulanti, T. L. Huu, and M. Schmitt, Carbon 44, 374 (2006).

${ }^{9}$ Y. Ando, S. Tobe, T. Saito, J. Sakurai, H. Tahara, and T. Yoshikawa, Thin Solid Films 457, 217 (2004).

${ }^{10}$ H. S. Shin and D. G. Goodwin, Appl. Phys. Lett. 66, 2909 (1995).

${ }^{11}$ M. C. Turchan and P. Mistry, U.S. Patent No. 5,554,415 (10 September 1996).

${ }^{12}$ P. Mistry and M. C. Turchan, U.S. Patent No. 5,731,046 (24 March 1998).

${ }^{13}$ H. Hirose and K. Komaki, European Patent Publication No. EP0324538 (19 July 1988).

${ }^{14}$ D. W. Zhang, Z. J. Liu, Y. Z. Wan, and J. T. Wang, Appl. Phys. A: Mater. Sci. Process. 66, 49 (1998).

${ }^{15}$ T. Abe, M. Suemitsu, and N. Miyamoto, J. Appl. Phys. 74, 3531 (1993).

${ }^{16}$ T. P. Thorpe, R. A. Weimer, and J. A. Freitas, Appl. Phys. Lett. 65, 2490 (1994).

${ }^{17}$ S. Takeuchi and M. Murakawa, Thin Solid Films 377, 290 (2000).

${ }^{18}$ J. B. Donnet, D. Paulmier, H. Oulanti, and T. L. Huu, Carbon 42, 2215 (2004).

${ }^{19}$ K. J. Yi, Y. F. Lu, and H. Ling, Proc. SPIE 6107, 610700 (2006).

${ }^{20}$ Y. W. Zheng, B. S. Luk, Y. F. Lu, W. D. Song, and Z. H. Mai, J. Appl. Phys. 90, 2135 (2001).

${ }^{21}$ D. R. Halfpenny and D. M. Kane, J. Appl. Phys. 86, 6641 (1999).

${ }^{22}$ D. Paulmier, T. L. Huu, and H. Zaidi, Surf. Sci. 377, 866 (1997).

${ }^{23}$ D. B. Oakes, J. E. Butler, K. A. Snail, W. A. Carrington, and L. M. Hanssen, J. Appl. Phys. 69, 2602 (1991).

${ }^{24}$ V. N. Strekalov, V. I. Konov, V. V. Kononenko, and S. M. Pimenov, Appl. Phys. A: Mater. Sci. Process. 76, 603 (2003).

${ }^{25}$ C. Z. Wang, K. M. Ho, M. D. Shirk, and P. A. Molian, Phys. Rev. Lett. 85, 4092 (2000).

${ }^{26}$ S. Preuss and M. Stuke, Appl. Phys. Lett. 67, 338 (1995). 